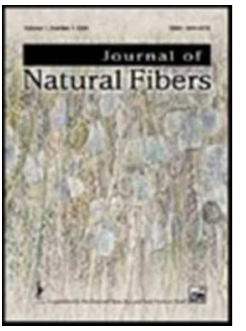

\title{
Evaluation of aging behaviour under salt-fog spray conditions of green sandwich structures
}

\begin{tabular}{|r|l|}
\hline Journal: & Journal of Natural Fibers \\
\hline Manuscript ID & WJNF-2018-0022.R1 \\
\hline Manuscript Type: & Original Article \\
\hline Keywords: & Sandwich, Aging, Salt fog, Agglomerate cork, Flax, Mechanical properties \\
\hline \multicolumn{2}{|c}{} \\
\hline
\end{tabular}

\section{SCHOLARONE ${ }^{m}$}

Manuscripts 


\title{
Evaluation of aging behavior under salt-fog spray conditions of green sandwich structures
}

\begin{abstract}
1 Abstract
2 In this paper, the aging resistance of sandwich structures made with cork agglomerate as core and

3 flax reinforced polymeric laminates as face sheets was investigated for the first time. In order to

4 evaluate their durability in a hostile environment, a sandwich plate was manufactured by vacuum

5 bagging technique and aged under salt-fog spray conditions, according to ASTM B 117 standard.

6 The evolution of the sandwich mechanical properties during the aging exposition was analyzed by

7 carrying out quasi-static flexural tests and Charpy impact tests both on unaged specimens and on

8 specimens aged for 10,25 and 60 days, respectively

9 The quasi-static experimental results showed that, despite the salt-fog exposition leads to clear

10 decrements in both maximum strength and modulus, the deformation capability of the sandwich

11 structure evidences a noticeable improvement. According to this last result, it was found that the

12 impact strength of the sandwich specimens was clearly increased after the salt-fog exposition

13 evidencing that the studied green sandwich maintains good toughness properties in a hostile 14 environment such as marine.
\end{abstract}

15

16

17

18

19 Keywords: Sandwich, aging, salt-fog, agglomerate cork, flax, mechanical properties 


\section{$1 \quad$ Introduction}

2 In the last decades sandwich structures have gained more and more attention in several engineering

3 fields such ship building (Cao and Grenestedt, 2004; Di Bella et al., 2012; Toftegaard and Lystrup, 4 2005), automotive (Brückmann et al., 2014; Hara and Ozgen, 2016), aerospace (Crump et al., 2010;

5 Hohe et al., 2012) and civil buildings (Mathijsen, 2013; Torre and Kenny, 2000) thanks to their

6 good features such as low weight and high flexural stiffness. This combination of properties is

7 strictly related to the stacking sequence of sandwich that is characterized by two external stiff and

8 strong skins made of fiber reinforced polymeric laminates bonded to a thick and lightweight central

9 layer named core. This last, made of low weight material (i.e., metallic and non-metallic

10 honeycombs, cellular foams or balsa wood), usually presents high shear and compression properties

11 in addition to low thermal and acoustic conductivity (Zenkert, 1997).

12 The need for sustainable materials with the aim to alleviate the environmental impact of engineering 13 materials and increase their end of life disposal options has definitely stimulated, over the last two 14 decades, a resurgent interest towards natural fibers as reinforcement of polymer matrix composites 15 (Yan et al., 2014). Also sandwich structures cannot be considered exempt from these environmental 16 concerns, especially if one considers their increasing use in several engineering fields, dictated by 17 the high flexural stiffness and lightweight coupled with additional benefits related to the specific 18 application, such as thermal and acoustic insulation, impact resistance, ease of forming and fire 19 retardation.

20 Cork agglomerate is a promising candidate as core material of sandwich structures for its good 21 characteristics. Cork is a natural material produced by the cork oak (Quercus suber L.) having good 22 features such as low density, high resistance to impact, low permeability to gases and liquids, low 23 thermal and acoustic conductivity, high compressive strength, good damping properties, chemical 24 stability and durability (Silva et al., 2005). Reis and Silva (Reis and Silva, 2009) analyzed the 
1 viability of using cork agglomerates as core materials of sandwich structures for aeronautical and

2 aerospace applications. In particular, they compared the mechanical performances of sandwich

3 structures with carbon/epoxy faces and cores of different cork agglomerates with that obtained with

4 similar specimens using traditional synthetic materials such as Rohacell ${ }^{\odot}$ and ECA honeycomb. The

5 experimental results evidenced that cork-based cores are suitable for sandwich applications. Castro

6 et al. (Castro et al., 2010) aimed to optimize the properties of cork agglomerates as ideal core

7 material for sandwich lightweight structures. To this scope, they manufactured cork agglomerate

8 using an epoxy resin as binder and compared its flexural properties with that of five commercial

9 cork agglomerates having different densities and two synthetic materials such as Nomex ${ }^{\odot}$ and

10 Rohacell $^{\odot}$. Moreover, the mechanical performances of sandwich structures with cork agglomerate

11 as core material and carbon/epoxy face sheets bonded together and cured in an autoclave were evaluated through three point banding tests and impact tests. Walsh et al. (Walsh et al., 2017)

13 evaluated the use of expanded agglomerate cork as core material in composite sandwich structures

14 with carbon fiber face sheets. In comparison to synthetic Rohacell ${ }^{\circledR}$ foam, expanded agglomerate 15 cork showed decrease in bending stiffness but noticeable improvements in acoustic, damping, and 16 impact damage resistance characteristics.

17 As well as coupled with skins made of carbon fiber reinforced polymers, cork agglomerate was also 18 used as core material of sandwich having polymer face sheets reinforced with natural fibers. In this 19 regard, a research work was done by Mancuso et al., 2015, that have investigated the flexural 20 stiffness and strength of sandwiches made with agglomerate cork core and flax reinforced epoxy 21 face sheets, to be used as eco-friendly structural components of small sailing boat. In particular, 22 they evidenced that manufacturing technology (i.e. hand lay-up, vacuum bagging and resin 23 infusion) determines different fiber volume fractions in the face sheets in addition to a significantly 24 different amount of resin soaked into the cork core, thus influencing the sandwich flexural 25 performances. The response to low velocity impacts of similar green sandwich specimens (i.e., 
1 flax/epoxy face sheets and agglomerated cork core) was compared to that of specimens made of

2 traditional synthetic core by Sarasini et al., 2016. The experimental results showed that the peculiar

3 deformation mechanism of cork (i.e., the collapse of cell walls) allows for absorption of high

4 amount of energy without a considerable extension of damage inside the core material. Moreover,

5 the authors stated that, through an effective tailoring of cork density and grain size, it would be

6 possible to reach peak loads and perforation energies comparable to that offered by high

7 performance core materials.

8 The flexural properties and water absorption behavior of cork agglomerate asymmetric sandwiches

9 (i.e., with one face sheet reinforced by basalt mineral fibers (Fiore et al., 2015) and other one by

10 flax fibers) were analyzed by Hoto et al., 2014. They also evaluated the effect of resin infiltration

11 between cork granules when the cork agglomerate is previously coated with a thin layer of resin to

12 prevent resin infiltration inside the core during vacuum bagging operation. The experimental results

13 showed that both core type and stacking sequence influence the flexural behavior of sandwich

14 panels. Furthermore, the sandwiches water absorption is mainly influenced by the core type.

15 Another paper concerning sandwich structures made of core cork agglomerate was done by Reis et

16 al. (Reis et al., 2010), who evaluated the effect of cork agglomerate density on the mechanical

17 properties (i.e., compressive, shear and bending) of panels having polyester based face sheets

18 reinforced by glass or jute fibers.

19 Overall, although several researchers have focused their efforts to investigate the behavior of 20 sandwich structures with cork agglomerate as core materials and polymeric face sheets reinforced 21 by natural fibers, at the best of our knowledge no one have yet studied the response of these green 22 structures in aggressive environments.

23 In this context, the present paper represents the first attempt to evaluate the aging behavior of green

24 sandwich structures exposed to salt-fog spray conditions. To this aim, a sandwich plate made of 25 cork agglomerate core and epoxy face sheets reinforced with unidirectional flax layers was exposed 
1 for 60 days to salt-fog environmental conditions, according to ASTM B 117 standard. Sandwich

2 specimens were subjected to quasi-static flexural tests and Charpy impact tests after 10, 25 and 60

3 days to compare their mechanical performances with that of unaged specimens.

4

\section{1. Material and methods}

6 A sandwich panel $(9 \mathrm{~mm} \times 30 \mathrm{~mm} \times 30 \mathrm{~mm})$ was manufactured through vacuum bagging technique 7 by using as core material cork agglomerate CORECORK NL20 (Amorim Cork Composites 8 Portugal) with nominal density and thickness equal to $200 \mathrm{~kg} / \mathrm{m}^{3}$ and $6 \mathrm{~mm}$, respectively. Polymer 9 facings, having stacking sequence $[0 / 90]_{\mathrm{s}}$ and nominal thickness $1.5 \mathrm{~mm}$, were made by using SX-8 10 EVO epoxy resin (Mates Italiana - Italy) and flax unidirectional fabrics with $190 \mathrm{~g} / \mathrm{m}^{2}$ areal weight 11 (Lineo - France). After an initial cure cycle at room temperature for 24 hours, the panel was post12 cured at $50{ }^{\circ} \mathrm{C}$ for 15 hours according to the supplier's recommendations. Table 1 shows the main 13 characteristics of raw materials.

14 After the manufacturing phase, the panel was exposed in a climatic chamber model DCTC 600 15 (Angelantoni - Italy) to salt-fog spray, for a whole period of 60 days. According to ASTM B 117 16 standard, it was used a salt fog with chemical composition of $5 \% \mathrm{NaCl}$ solution (i.e., $\mathrm{pH}$ between 176.5 and 7.2) and temperature was set equal to $35^{\circ} \mathrm{C}$. The panel was taken out from the chamber after 1810,25 and 60 days in order to cut prismatic samples (25 $\mathrm{mm} \times 250 \mathrm{~mm}$ size) by using a diamond 19 saw. Quasi-static three point bending tests were performed according to ASTM D790 standard, 20 using a Universal Testing Machine, model Z005 (Zwick/Roell - Germany) equipped with a $5 \mathrm{kN}$ 21 load-cell, setting the span length and the crosshead speed equal to $120 \mathrm{~mm}$ and $5.12 \mathrm{~mm} / \mathrm{min}$, 22 respectively. For each condition investigated, five specimens were tested. 
1 Impact tests were carried out using a Charpy test machine model 9050 (CEAST - Italy), equipped

2 with a pendulum of potential energy equal to $25 \mathrm{~J}$ and impact speed of $3.8 \mathrm{~m} / \mathrm{s}$. Five un-notched

3 prismatic samples $(80 \mathrm{~mm} \times 10 \mathrm{~mm})$ were tested for each aging condition.

\section{2. Results and discussion}

\subsection{Quasi-static flexural tests}

The typical stress versus strain curves of green sandwiches for each aging condition are shown in Figure 1.

By considering the unaged specimen (i.e., F_0), a linear trend in the stress-strain curve can be observed up to about $24 \mathrm{MPa}$ and $0.8 \%$ of stress and strain, respectively. The constant slope of the curve indicates that evident cracks have not yet appeared neither in the skins nor in the cork core of the sandwich structure. After this first step, the unaged specimen shows a non-linear behavior just before reaching the maximum stress values: i.e., the curves slope decreases at increasing deflection due the initiation of cracks localized within the area of the upper skin in contact with the loading tool. For stress and strain equal to about $30 \mathrm{MPa}$ and $1.4 \%$, a stress drop happens mainly due to the indentation of the punch on the upper face sheet (Figure 2a).

After that, despite the upper skin is completely collapsed in the area around the punch, the unaged sandwich shows a quite constant residual strength (i.e., about $25 \mathrm{MPa}$ ). In this stage, slight collapses can be observed due to the compression fracture of the core, as evidenced in Figure $2 \mathrm{~b}$.

The observed residual resistance is due to the lower skin that is yet able to support the applied load. Finally, a sudden load drop is registered at strain equal to about $4.1 \%$ due to the tensile failure of the lower skin (Figure 2c).

A similar behavior can be observed for sandwich specimens exposed to salt-fog spray condition: i.e., the aged specimens experienced the same failure mechanisms (with the same timeline) already described for unaged sandwich specimens. Consequently, the stress-strain curves are quite similar 
1 regardless the aging condition. Nevertheless, the exposition of the sandwich specimens to salt-fog

2 spray leads to changes in the sandwich mechanical behavior, which need to be highlighted.

3 More in detail, it is worth noting that the linear stage of the curve becomes narrower by increasing

4 the aging time. In particular, the specimens exposed to salt-fog spray for 10 days evidenced a

5 constant slope in the stress-strain curve just until stress and strain values are equal to about $10 \mathrm{MPa}$

6 and $0.5 \%$, respectively. On the other hand, the specimens aged for 25 and 60 days showed a linear

7 elastic trend even more limited (i.e., for stress and strain values up to about $5 \mathrm{MPa}$ and $0.3 \%$,

8 respectively). Moreover, the aged specimens experienced a wider non-linear behavior before

9 reaching the maximum stress values, with increasing the aging time. This means that the exposition to $\mathrm{NaCl}$ solution spray accelerates the failure initiation and propagation within the upper skin (i.e.,

11 in the area in contact with the loading tool) thus leading to the reduction of the stress-strain curve 12 slope and, consequently, of the sandwiches flexural stiffness. Furthermore, the slope of the linear 13 stage of the stress-strain curve decreases with increasing the aging time exposition, thus leading to 14 the reduction of the equivalent Young modulus (i.e., evaluated taking into account the isotropic 15 structure, equivalent to the composite (Di Bella et al., 2012)). In particular, the sandwich structures 16 evidenced a reduction of the flexural modulus of about $57 \%$ after 60 days of salt-fog exposition 17 (i.e., from $3.28 \mathrm{GPa}$ to $1.41 \mathrm{GPa}$ ), as showed in Table 2 . This decrement can be mainly attributed to absorb high amounts of moisture after exposure to water environments that contribute to soften the sandwich structure. Since it was shown in an our previous paper (Fiore et al., 2016) that the 21 saturation level of similar epoxy flax reinforced laminates is reached after about 700 hours (i.e., 29 22 days) of salt-fog exposition, the further decrement in the flexural stiffness experienced between 25 23 and 60 days of exposition can be attributed to the water absorbed by the cork agglomerate core 24 (Lagorce-Tachon et al., 2015). 
1 As well as for the unaged sandwich, after the non-linear part of the curve, the aged specimens

2 experienced a gradual stress drop, due to the indentation failure of the upper skin. It worth notice

3 that, regardless the aging time, the composite skin- core interface well resists to the onset stress

4 field thus proving its good quality. The maximum strength showed by the aged structures decreases

5 by increasing the aging time exposition. In particular, after 60 days of aging, the aged sandwich

6 specimens showed 47\% lower maximum strength than unaged specimens (15.6 MPa versus 29.5

$7 \mathrm{MPa}$ ). This decrement can be explained taking into account the softening effect of the upper flax

8 reinforced skin due to the salt-fog.

9 Even the aged sandwich specimens showed a residual strength after the indentation failure of the

10 upper skin. In particular, the post-failure residual resistance of the 10 days-aged specimens is about

$1130 \%$ lower than that of unaged specimen (i.e., $17 \mathrm{MPa}$ versus $25 \mathrm{MPa}$ ), due to exposition to salt-fog

12 condition. On the other hand, the sandwich structures aged for 25 and 60 days showed similar

13 residual strength (i.e., $14 \mathrm{MPa}$ ), about 44\% lower in comparison to the unaged sandwich.

14 Despite both modulus and maximum strength decrease with aging exposition, it is worth noting that

15 aged specimens showed greater ductility in comparison to unaged sandwich, evidenced by the 16 increases of both the strain at maximum strength and the strain at break (Figure 1). In particular, the 17 strain at maximum strength of aged specimens is found to be $32 \%, 45 \%$ and $71 \%$ higher than that of 18 unaged sandwich, after 10, 25 and 60 days of aging exposition, respectively. Furthermore, the 19 plateau region showed by the sandwich specimens (regardless the aging condition) between the 20 main stress drop (i.e., due to the indentation of the upper skin) and the final failure (i.e., tensile 21 break of the lower skin) becomes wider with the exposition to the salt-fog environment. This 22 significant enhancement in the plateau regime contribute is strictly related to the strain at break 23 increment (i.e. $+50 \%$ than unaged specimens) experienced by the sandwich structures aged for 60 24 days. This involves an extension of the plateau region up to very high deformation values (Fiore et 
1 al., 2016). Figure 3 shows the average values and the related deviations standard of the strain at

2 maximum strength and strain at break at varying the aging time exposition.

3 As discussed previously, the post-failure behavior (i.e., after the gradual stress drop due to the

4 indentation of the upper skin) is due to the lower skin that is yet able to support the applied load.

5 This means that the residual deformation capability showed by the lower skin allows the bending of

6 the entire sandwich structure that maintains a residual resistant until the lower skin fails in tensile

7 mode.

8 During the aging exposition, in addition to the detrimental effect on the sandwich flexural

9 properties (i.e., maximum strength and modulus) of the salt-fog aging, the water absorption of the

10 flax fibers leads to the plasticization of the matrix and, as a consequence, to the increase of the

11 mobility of the polymer chains (Fiore, Calabrese, et al., 2017). This phenomenon is responsible for

12 the increments both of the strain at maximum strength and of the strain at break of the aged

13 sandwich specimens.

14 This aspect is of upmost importance since, despite the salt-fog aging clearly caused decrement of

15 flexural properties like stiffness and maximum strength, noticeable enhancement in the post-failure

16 deformation capability experienced by the sandwich structures can be observed at increasing the

17 aging exposition.

18 Overall, the quasi-static characterization evidenced that the salt-fog exposition leads both to (i) a 19 reduction of maximum stress capability due to salt fog actions such as chemical degradation or 20 physical damages and to (ii) an increment of the maximum deformation capability mainly due to the 21 water absorption. These effects will influence significantly the impact properties of the sandwich 22 structures exposed to salt-fog aging environment, as already showed by Fiore et al., 2016. 


\subsection{Charpy impact tests}

2 As shown in Table 3, it is evident that the impact energy of the green sandwich structures increases

3 at increasing the aging exposition time. In particular, it was found that the impact strengths of the

410 days, 25 days and 60 days aged specimens are 14\%, 30\% and $46 \%$ higher than that of unaged

5 specimens, respectively. Instead, no noticeable change in the peak load is observed after the salt-fog

6 exposition.

7 This important result is in complete accordance with the variation of the quasi-static deformation

8 capability (i.e., both the strain at maximum strength and the strain at break) experienced by the

9 green sandwich structures during the aging exposition. Hence, it can be stated that the improvement

10 of the impact energy during the salt-fog exposition is mainly related to the plasticization effect due

11 to the water exposition that leads to the increase of the polymer chains mobility. This means that the

12 increment in plastic deformation is predominant in comparison to the maximum strength reduction

13 because of the high amount of water absorbed by the green sandwich structures.

14 Consequently, the resin plasticization favored by the hydrophilic nature of flax fiber can be 15 considered as the predominant phenomenon that influences the impact properties of the sandwiches, 16 leading to an improvement of their toughness with increasing aging time. In addition to this, it is 17 widely known that when exposed to moisture, lignocellulosic fibers became more ductile thus 18 contributing to the enhancement of the composite toughness (Meredith et al., 2013). Similar results 19 were obtained for composite laminates reinforced with lignocellulosic fibers exposed to salt-fog or 20 humid environments (Fiore et al., 2016; Fiore, Scalici, et al., 2017; Živković et al., 2017)

21 Further information can be extrapolated by observing the load-deflection impact curves of unaged 22 and 60 day-aged specimens, shown in Figure 4. The load-deflection curves of 10 days-aged and 25 23 days-aged specimens are not shown since they are almost identical to that of 60 days-aged 24 specimen. 
1 Since impact test and quasi-static test have been carried out under the same load configuration (i.e.

2 three-point bending), the same failure modes evidenced by the sandwich structures during the quasi-

3 static tests were experienced during the impact tests. In more detail, it is worth noting (Figure 4)

4 that both specimens evidence three load drops during the impact. In particular, the first one,

5 occurred at about the same load and deflection values (i.e., $250 \mathrm{~N}$ and $1.1 \mathrm{~mm}$, respectively)

6 regardless the aging condition, is related to the indentation of the upper skin. After that, all the

7 specimens showed a gradual decrement of the load until a second sudden load drop that happens at

8 about $11 \mathrm{~mm}$ of deflection. This trend can be attributed to the compressive failure of the cork core.

9 After the second load drop, both sandwich specimens show residual resistance due to the lower skin

10 that, as already discussed for the quasi-static test, is the last undamaged element within the

11 sandwich structure, being yet able to support the applied load. It is evident, by observing the last

12 stage of the curve, how the exposition to the salt-fog environment modifies the impact energy

13 capability of the sandwich specimens. The plasticization effect due to the water absorption leads to

14 the increment of the lower skin deformation capability thus increasing the toughness of the whole

15 sandwich structure. In particular, while the final load drop happened at about $16 \mathrm{~mm}$ of deflection

16 for the unaged sandwich specimen, the tensile failure of the lower skin of the 60 days-aged

17 specimens occurred at about twice deflection (i.e., $~ 32 \mathrm{~mm}$ ).

18 This means that the increment of the sandwich toughness after the salt-fog exposition is not due to 19 an increment of the peak load capability, which remains almost constant as shown in Table 3, but to 20 the increased deformation capability of the lower skin.

\section{Conclusions}

23 In the present paper the salt-fog aging behavior of green sandwich structures made of agglomerate 24 cork core and flax/epoxy face sheets was evaluated for the first time. To this aim, sandwich 
1 specimens were exposed to salt spray fog environment and the evolution of the mechanical

2 performances was assessed by performing quasi-static flexural tests and Charpy impact tests both

3 on unaged specimens and on specimens aged for 10, 25 and 60 days, respectively.

4 The quasi-static flexural characterization evidenced that both maximum strength and modulus

5 decrease during the aging exposition whereas both the strain at maximum strength and the strain at

6 break increase during the entire aging campaign, evidencing the beneficial effect of the salt-fog

7 exposition on the sandwiches deformation capability.

8 On the other hand, the impact results showed that the peak load slightly decreases whereas a

9 noticeable improvement of impact strength is achieved by increasing the aging time exposition.

10 It can be drawn that eco-friendly sandwiches made of cork core and flax reinforced epoxy skins

11 could be used in semi-structural applications when exposed to hostile environments such as marine 12 one, especially if they have to support impact loads.

\section{Acknowledgments}

16 This research follows from Project “TRIM - Technology and Industrial Research for Marine 17 Transport” (PON “R\&C” 2007/2013). 
4 References

5 Brückmann S., Friedrich HE., Kopp G., and Kriescher M. 2014. Sandwich Lightweight Design in

Di Bella G., Calabrese L., and Borsellino C. 2012. Mechanical characterisation of a glass/polyester sandwich structure for marine applications. Materials \& Design, 42: 486-494.

Fiore V., Scalici T., Di Bella G., and Valenza A. 2015. A review on basalt fibre and its composites. Composites Part B: Engineering,

Fiore V., Scalici T., Calabrese L., Valenza A., and Proverbio E. 2016. Effect of external basalt layers on durability behaviour of flax reinforced composites. Composites Part B: Engineering, 84: $258-265$.

Fiore V., Scalici T., Badagliacco D., Enea D., Alaimo G., and Valenza A. 2017. Aging resistance of bio-epoxy jute-basalt hybrid composites as novel multilayer structures for cladding. Composite Structures, 160: 1319-1328.

Fiore V., Calabrese L., Proverbio E., Passari R., and Valenza A. 2017. Salt spray fog ageing of 
1 hybrid composite/metal rivet joints for automotive applications. Composites Part B: $2 \quad$ Engineering, 108: 65-74.

3 Hara D., and Ozgen GO. 2016. Investigation of Weight Reduction of Automotive Body Structures

Lagorce-Tachon A., Karbowiak T., Champion D., Gougeon RD., and Bellat JP. 2015. Mechanical properties of cork: Effect of hydration. Materials and Design, 82: 148-154.

Mancuso A., Pitarresi G., and Tumino D. 2015. Mechanical behaviour of a green sandwich made of flax reinforced polymer facings and cork core. Procedia Engineering, 109: 144-153.

Mathijsen D. 2013. Composite sandwich structures: the new milestone in bridge building. Reinforced Plastics, 57(6): 17-23.

Meredith J., Coles SR., Powe R., Collings E., Cozien-Cazuc S., Weager B., Müssig J., and Kirwan K. 2013. On the static and dynamic properties of flax and Cordenka epoxy composites. Composites Science and Technology, 80: 31-38.

Reis L., and Silva A. 2009. Mechanical Behavior of Sandwich Structures using Natural Cork Agglomerates as Core Materials. Journal of Sandwich Structures \& Materials, 11(6): 487500.

Reis L., Carvalho P., Alves C., and Freitas M. 2010. Mechanical behaviour of sandwich beams manufactured with glass or jute fiber in facings and cork agglomerates as core. Materials Science Forum, 636-637: 245-252. 
1 Sarasini F., Tirillò J., Lampani L., Valente T., Gaudenzi P., and Scarponi C. 2016. Dynamic

2 response of green sandwich structures. Procedia Engineering, 167: 237-244.

Silva SP., Sabino MA., Fernandes EM., Correlo VM., Boesel LF., and Reis RL. 2005. Cork: properties, capabilities and applications. International Materials Reviews, 50(6): 345-365.

Toftegaard H., and Lystrup A. 2005. Design and test of lightweight sandwich T-joint for naval ships. Composites Part A: Applied Science and Manufacturing, 36(8): 1055-1065.

Torre L., and Kenny JM. 2000. Impact testing and simulation of composite sandwich structures for civil transportation. Composite Structures, 50(3): 257-267.

Walsh J., Kim HI., and Suhr J. 2017. Low velocity impact resistance and energy absorption of environmentally friendly expanded cork core-carbon fiber sandwich composites. Composites Part A: Applied Science and Manufacturing, 101: 290-296.

Yan L., and Chouw N. 2015. Effect of water, seawater and alkaline solution ageing on mechanical properties of flax fabric/epoxy composites used for civil engineering applications. Construction and Building Materials, 99: 118-127.

Yan L., Chouw N., and Jayaraman K. 2014. Flax fibre and its composites - A review. Composites Part B: Engineering, 56: 296-317.

Zenkert D. 1997. The handbook of sandwich construction.

Živković I., Fragassa C., Pavlović A., and Brugo T. 2017. Influence of moisture absorption on the impact properties of flax, basalt and hybrid flax/basalt fiber reinforced green composites. Composites Part B: Engineering, 111: 148-164. 


\section{Figure Captions}

2 Figure 1. Typical stress-strain curves of green sandwich structures at varying aging 3 exposition.

4 Figure 2. Failure mechanisms of unaged green sandwiches: (a) indentation failure of the 5 upper facing sheet, (b) compression failure of the cork agglomerate core, (c) tensile failure of 6 the lower facing sheet.

$7 \quad$ Figure 3. (a) Strain at maximum stress and (b) strain at break of green sandwich structures at 8 varying aging exposition.

9 Figure 4. Load- deflection impact curves for unaged and 60 days aged sandwiches.

\section{Table Captions}

14 Table 1. Main characteristics of raw materials.

15 Table 2. Flexural properties at varying aging condition.

16 Table 3. Impact strength at varying aging exposition. 
Table 1. Main characteristics of raw materials

\begin{tabular}{|c|c|c|c|c|c|}
\hline \multicolumn{2}{|c|}{ Cork agglomerate } & \multicolumn{2}{|l|}{ Epoxy resin } & \multicolumn{2}{|c|}{ Flax Fabric } \\
\hline $\begin{array}{c}\text { Compressive strength } \\
{[\mathrm{MPa}]}\end{array}$ & 0.3 & $\begin{array}{c}\text { Tensile strength } \\
{[\mathrm{MPa}]}\end{array}$ & $65-75$ & $\begin{array}{l}\text { Thickness } \\
{[\mathrm{mm}]}\end{array}$ & 0.2 \\
\hline $\begin{array}{c}\text { Compressive modulus } \\
{[\mathrm{MPa}]}\end{array}$ & 5.1 & $\begin{array}{l}\text { Tensile modulus } \\
{[\mathrm{MPa}]}\end{array}$ & $\begin{array}{l}2400- \\
3000\end{array}$ & $\begin{array}{c}\text { Areal weight } \\
{\left[\mathrm{g} / \mathrm{m}^{2}\right]}\end{array}$ & 190 \\
\hline $\begin{array}{c}\text { Shear strength } \\
{[\mathrm{MPa}]}\end{array}$ & 0.9 & Shore Hardness & $86-90$ & $\begin{array}{l}\text { Areal volume } \\
{\left[\mathrm{mm}^{3} / \mathrm{mm}^{2}\right]}\end{array}$ & 0.131 \\
\hline $\begin{array}{c}\text { Shear modulus } \\
{[\mathrm{MPa}]}\end{array}$ & 5.9 & $\begin{array}{c}\text { Gel time at } 25^{\circ} \mathrm{C} \\
{[\mathrm{h}]}\end{array}$ & $6-8$ & Yarns per $\mathrm{cm}$ & 42.5 \\
\hline $\begin{array}{c}\text { Thermal conductivity } \\
{[\mathrm{W} / \mathrm{mK}]}\end{array}$ & 0.042 & $\begin{array}{c}\text { Glass transition temperature } \\
{\left[{ }^{\circ} \mathrm{C}\right]}\end{array}$ & $75-85$ & $\begin{array}{c}\text { Fiber density } \\
{\left[\mathrm{g} / \mathrm{cm}^{3}\right]}\end{array}$ & 1.45 \\
\hline
\end{tabular}


Table 2. Flexural properties at varying aging condition

\begin{tabular}{|c|c|c|c|c|c|c|}
\hline $\begin{array}{c}\text { Aging time } \\
\text { [days] }\end{array}$ & $\begin{array}{c}\text { Maximum strength } \\
\text { [MPa] }\end{array}$ & Retention & Modulus [GPa] & Retention & $\begin{array}{c}\text { Strain at } \\
\text { maximum } \\
\text { strength } \\
{[\%]}\end{array}$ & Retention \\
\hline 0 & $29.5 \pm 0.8$ & 1 & $3.28 \pm 0.27$ & 1 & $1.44 \pm 0.04$ & 1 \\
\hline 10 & $20.6 \pm 1.8$ & 0.7 & $2.14 \pm 0.13$ & 0.65 & $1.90 \pm 0.05$ & 1.32 \\
\hline 25 & $15.7 \pm 0.9$ & 0.53 & $1.81 \pm 0.06$ & 0.55 & $2.09 \pm 0.21$ & 1.45 \\
\hline 60 & $15.6 \pm 0.7$ & 0.53 & $1.41 \pm 0.29$ & 0.43 & $2.46 \pm 0.57$ & 1.71 \\
\hline
\end{tabular}


2

3

4

5

6

7

8

9

10

11

12

13

14

15

16

17

18

19

20

21

22

23

24

25

26

27

28

29

30

31

32

33

34

35

36

37

38

39

40

41

42

43

44

45

46

47

48

49

50

51

52

53

54

55

56

57

58

59

60

Table 3. Impact strength at varying aging exposition

\begin{tabular}{|c|c|c|c|c|}
\hline Aging time [days] & Impact strength $\left[\mathrm{kJ} / \mathbf{m}^{\mathbf{2}}\right]$ & Retention & Peak load [N] & Retention \\
\hline 0 & $38.1 \pm 4.7$ & 1 & $248.0 \pm 7.9$ & 1 \\
\hline 10 & $43.3 \pm 3.5$ & 1.14 & $244.6 \pm 6.7$ & 0.99 \\
\hline 25 & $49.5 \pm 3.8$ & 1.30 & $240.1 \pm 11.4$ & 0.97 \\
\hline 60 & $55.5 \pm 4.0$ & 1.46 & $236.1 \pm 14.0$ & 0.95 \\
\hline
\end{tabular}




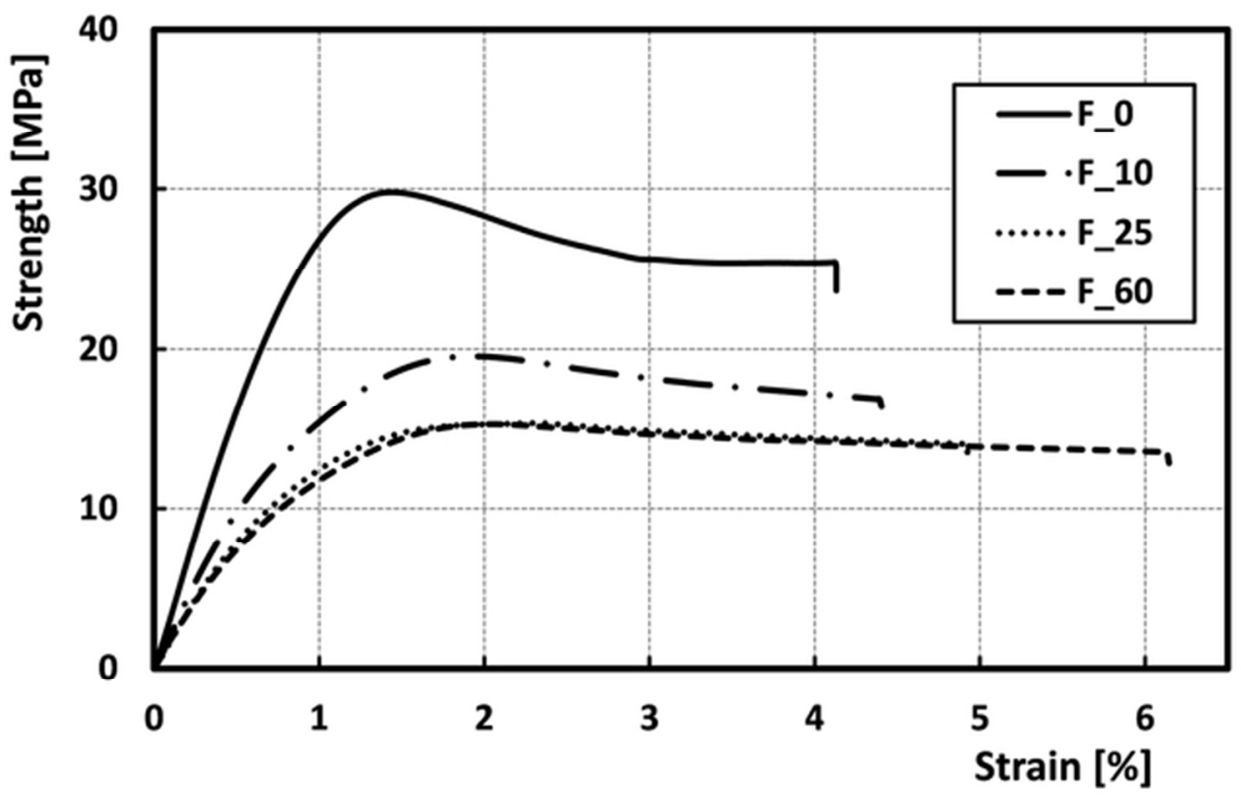

Figure 1

$56 \times 35 \mathrm{~mm}(300 \times 300$ DPI $)$ 

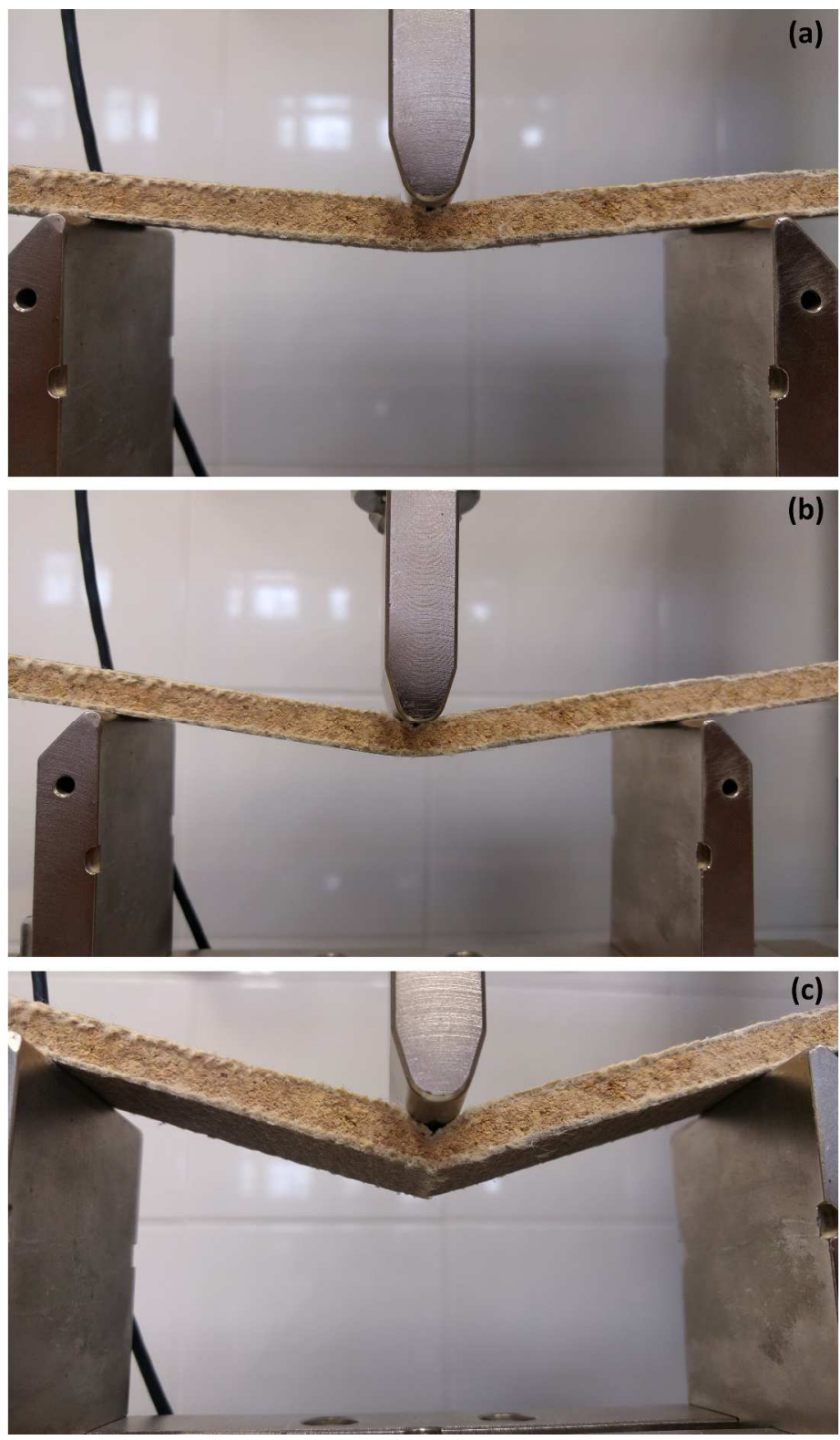

Figure 2

$239 \times 411 \mathrm{~mm}(300 \times 300 \mathrm{DPI})$ 

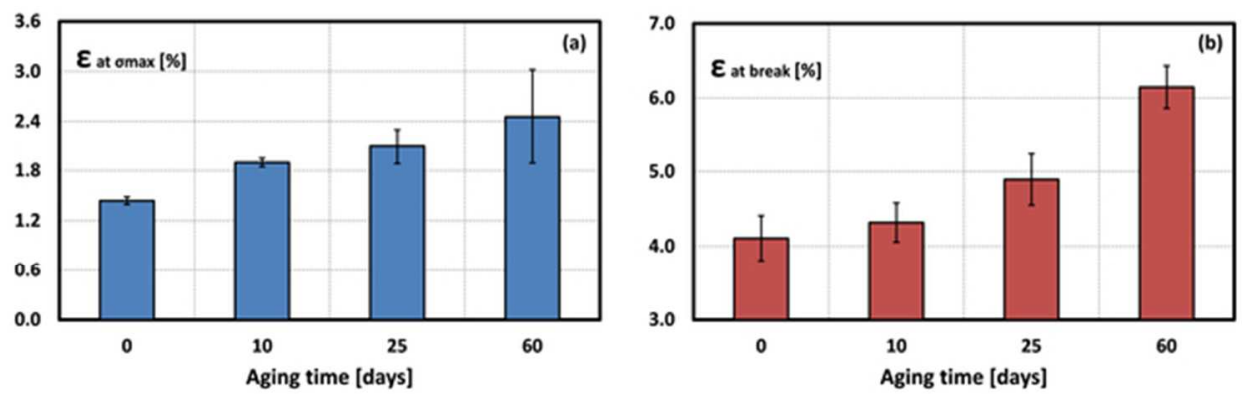

Figure 3

$56 \times 16 \mathrm{~mm}(300 \times 300 \mathrm{DPI})$ 


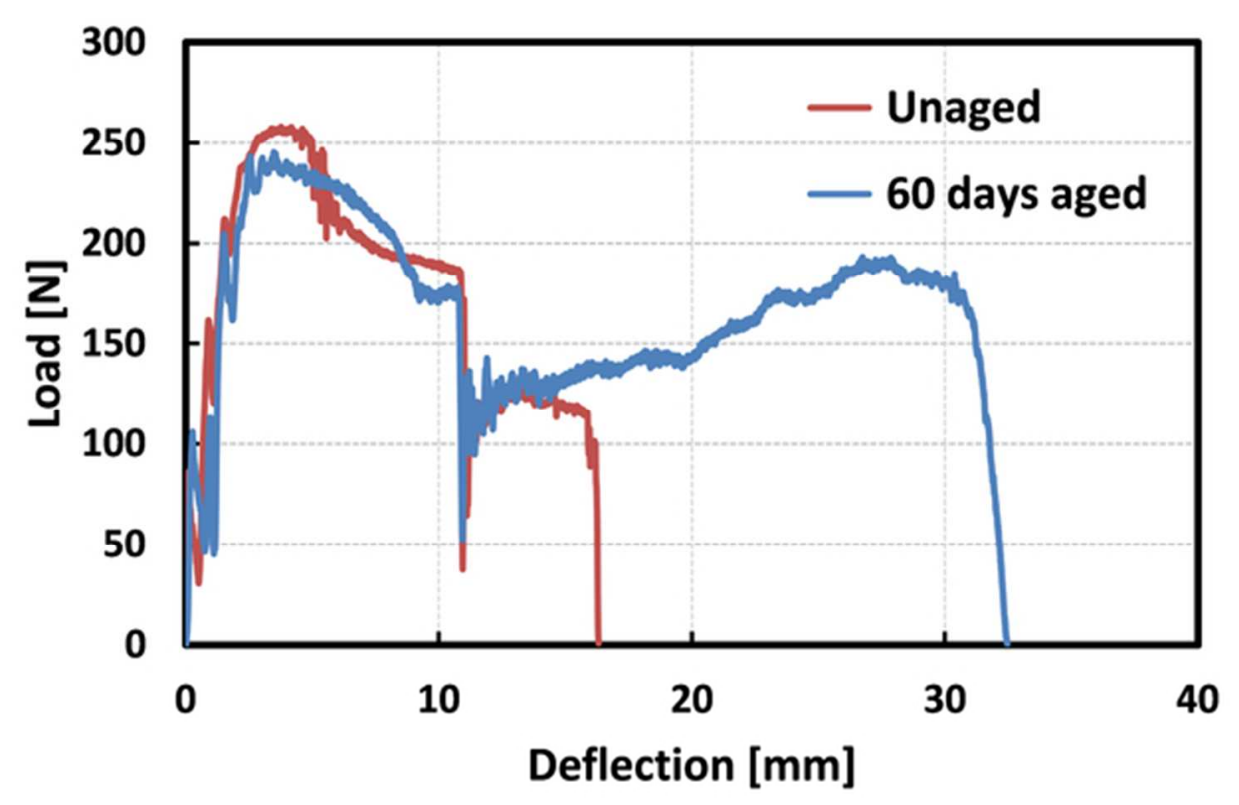

Figure 4

$55 \times 34 \mathrm{~mm}(300 \times 300$ DPI $)$ 